\title{
Feasibility of Brachial Plexus Schwannoma Enucleation With Intraoperative Neuromonitoring
}

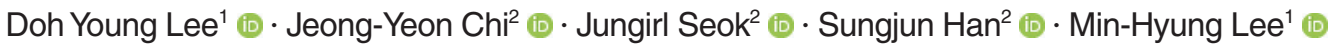 \\ Woo-Jin Jeong ${ }^{2}$ (D) $\cdot$ Young Ho Jung ${ }^{2}$ (D) \\ ${ }^{1}$ Department of Otorhinolaryngology-Head and Neck Surgery, SMG-SNU Boramae Medical Center, Seoul; \\ ${ }^{2}$ Department of Otorhinolaryngology-Head and Neck Surgery, Seoul National University Bundang Hospital, Seongnam, Korea
}

\begin{abstract}
Objectives. To evaluate the feasibility of brachial plexus schwannoma enucleation under intraoperative neuromonitoring.
Methods. Five patients who were treated for brachial plexus schwannoma under intraoperative neuromonitoring from 2008 to 2018 were included in this retrospective review. Neuromonitoring was performed with a $100-\mu \mathrm{V}$ event threshold of the neuromonitoring system (NIM-2 or 3) at the deltoid, biceps brachii, triceps brachii, and brachioradialis muscles. Patient characteristics, tumor size and location, intraoperative neuromonitoring findings, and postoperative function were evaluated.

Results. The intraoperative neuromonitoring findings were in accordance with the preoperative assessment of the included nerve root. Three patients had no postoperative morbidity, one patient had temporary paresthesia of the forearm for 2 months, and one patient mild loss of grip strength for 1 month.

Conclusion. Intraoperative neuromonitoring of the arm and forearm muscles during enucleation of brachial plexus schwannoma promoted confident and successful surgery with minimal postoperative morbidity.
\end{abstract}

Keywords: Brachial Plexus; Schwannoma; Neurilemmoma: Enucleation; Neuromonitoring; Feasibility Study

\section{INTRODUCTION}

Schwannoma is a benign neuroma composed of Schwann cells, which surround peripheral, cranial, and autonomic nerves. Schwannomas account for only $5 \%$ of all benign soft tissue tumors, but as many as $25 \%$ to $45 \%$ of schwannomas occur in the head and neck [1]. Due to the diversity of nerve function in the head and neck, the signs and symptoms of schwannoma in this region vary according to the nerve of origin and size of the tumor at presentation $[2,3]$. Because patients with schwannoma of the head and neck generally do not experience symptoms related to the function of the original nerve until the tumor reaches a cer-

\footnotetext{
- Received August 5, 2019

Revised October 21, 2019

Accepted November 8, 2019

- Corresponding author: Young Ho Jung

Department of Otorhinolaryngology-Head and Neck Surgery, Seoul

National University Bundang Hospital, 82 Gumi-ro 173beon-gil,

Bundang-gu, Seongnam 13620, Korea

Tel: +82-31-787-7413, Fax: +82-31-787-4057

E-mail: entist@naver.com
}

tain size, the main reason for treatment of schwannoma in this region is a palpable neck mass. The preoperative diagnosis of schwannoma is challenging, as computed tomography (CT), magnetic resonance imaging (MRI), and ultrasound-guided fine needle aspiration all have relatively low accuracy $[4,5]$. Consequently, a definitive diagnosis is achieved only upon histologic inspection of excised tumor specimens [6].

Primary tumors of the brachial plexus are extremely rare, accounting for no more than $5 \%$ of all tumors in the upper extremities [7]. Schwannoma arising in the brachial plexus is always a challenge for the surgeon because of the neuroanatomical complexity of this area. Nonetheless, surgical resection is usually recommended, with enucleation being the preferred operative technique for functional and oncologic safety. Because of the intimate relationship of the tumor with the nerve of origin, it is often difficult to preserve the function of the nerve [8]. This prospect is a stressful one for both the patient and the surgeon, and considering the complexity of the brachial plexus and the potential for surgical morbidity, neuromonitoring may be highly advantageous for identification and preservation of the affected

Copyright $\odot 2020$ by Korean Society of Otorhinolaryngology-Head and Neck Surgery.

This is an open-access article distributed under the terms of the Creative Commons Attribution Non-Commercial License (https://creativecommons.org/licenses/by-nc/4.0)

which permits unrestricted non-commercial use, distribution, and reproduction in any medium, provided the original work is properly cited. 


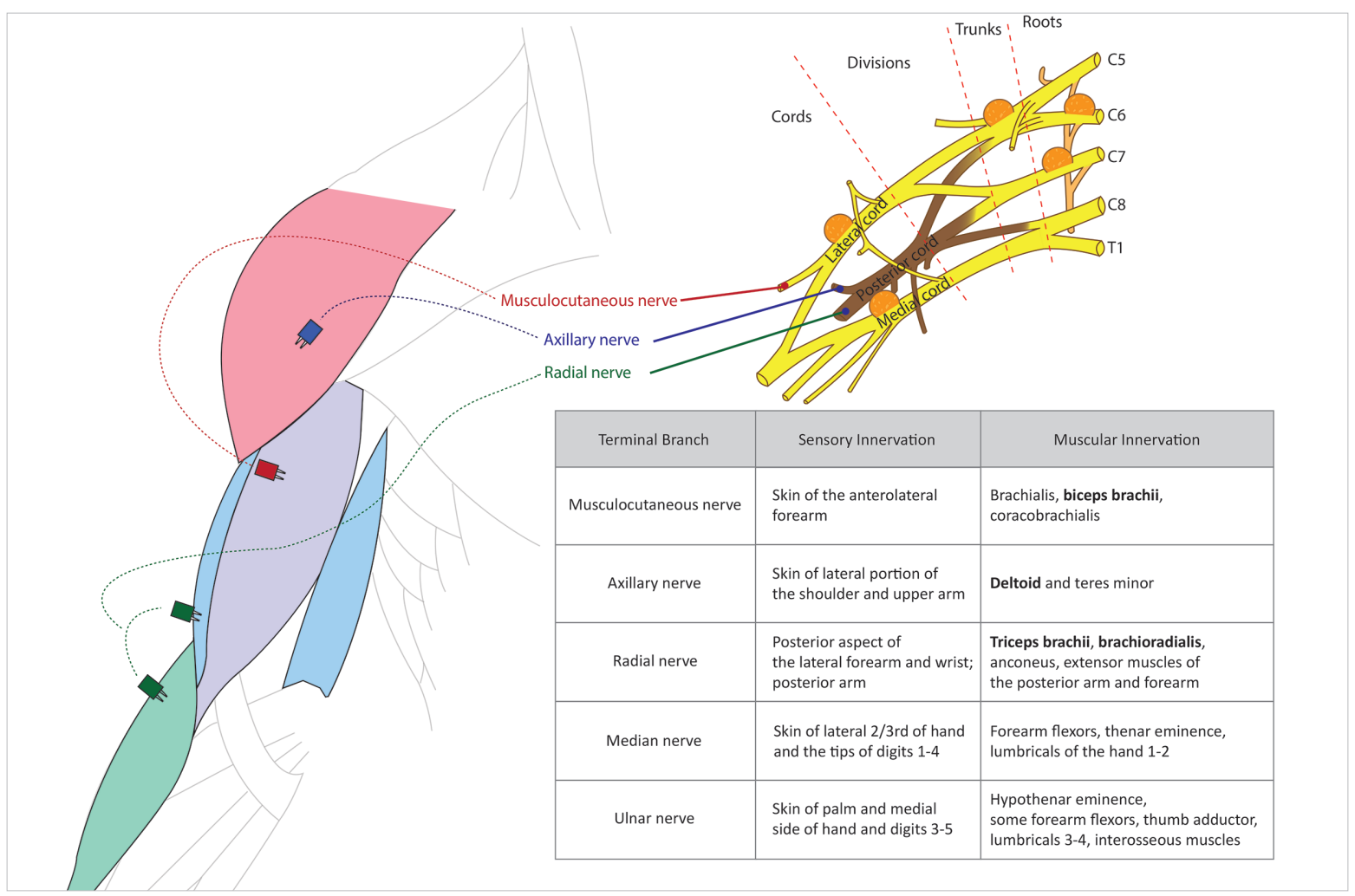

Fig. 1. Schematic diagram of the muscles to be monitored, their innervation, and the locations of the tumor in five cases. The table describes the innervation of the arm and the muscles controlled by each of the nerves.

nerve and the surrounding nerves. In this study, we aimed to descriptively analyze surgical outcomes and the feasibility of brachial plexus schwannoma removal under intraoperative neuromonitoring.

\section{MATERIALS AND METHODS}

\section{Ethical considerations}

This study was conducted in accordance with the principles of the Declaration of Helsinki. The study protocol was reviewed and approved by the Institutional Review Board of Seoul Na-

\section{H I G H L I E G H T S}

- This study aimed to evaluate the feasibility of brachial plexus schwannoma enucleation under intraoperative neuromonitoring.

- Intraoperative neuromonitoring of the arm and forearm muscles during enucleation of brachial plexus schwannoma promoted confident and successful surgery with minimal postoperative morbidity.

- This is the first study to elucidate the benefits of applying intraoperative neuromonitoring in brachial schwannoma enucleation. tional University Bundang Hospital (IRB No. 20-2018-42), and a waiver of informed consent was granted due to the retrospective design of the study.

\section{Patients}

Five patients who were treated for brachial plexus schwannoma under intraoperative neuromonitoring from 2008 to 2018 were included in this retrospective study. All patients were operated by single surgeon (YHJ) and age, sex, tumor size and location, preoperative symptoms, CT or MRI findings, intraoperative findings, and postoperative function were evaluated and descriptively analyzed to assess the feasibility of schwannoma enucleation under neuromonitoring.

\section{Surgical technique and hospital course}

Tumor location and corresponding nerves were assessed according to preoperative imaging findings. Surgery was performed by a transcervical approach with the patient under general anesthesia. Neuromonitoring was performed with a two-channel (one case) or four-channel (four cases) nerve integrity monitor (NIM2 or -3 , Medtronic, Memphis, TN, USA). The two-channel monitor (NIM-2) could be used to monitor two muscles. When using the four-channel device (NIM-3), electrodes were placed in the muscles of upper arm and forearm, including deltoid, biceps brachii, triceps brachii, and brachioradialis (Fig. 1) and patients 

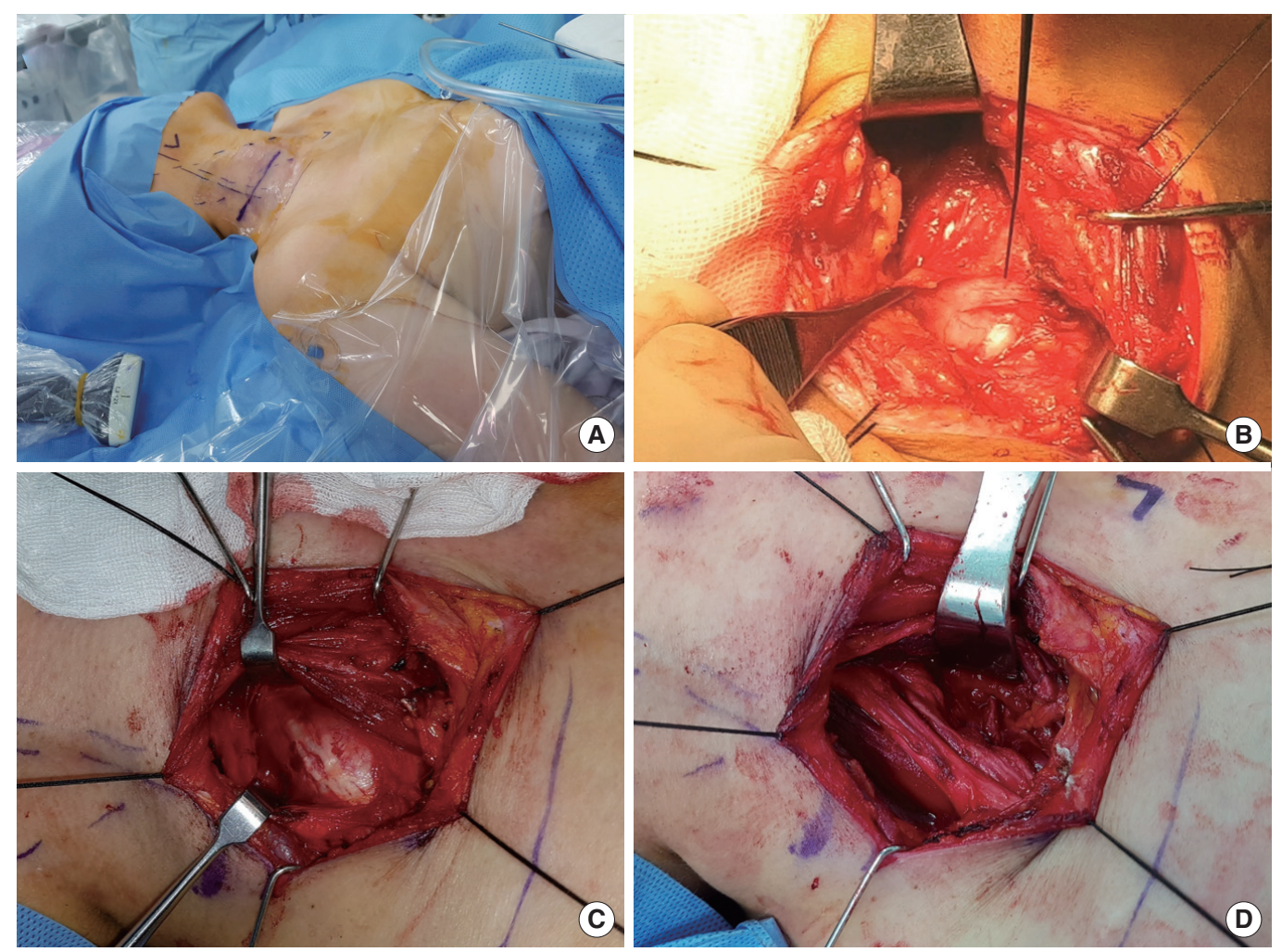

Fig. 2. Surgical technique. Exposure of the shoulder and arm is essential because muscle twitching can be observed during nerve stimulation (A). Neuromonitoring was performed with a two-channel (one case) or four-channel (four cases) nerve integrity monitor (NIM-2 or -3, Medtronic, Memphis, TN, USA) and a unipolar stimulating probe was used to stimulate the tumor or the nerves before identification and enucleation of the mass $(B, C)$. After enucleation of the tumor, stimulation of the nerve was performed to confirm neural integrity (D).

underwent continuous electromyography (EMG) during the surgery. Position of electrodes can be changed according to the location of mass. Neck, shoulder, and arm were exposed (without skin preparation with antiseptics) to observed muscle twitching during the operation (Fig. 2A). In addition, a unipolar stimulating probe was used to stimulate the tumor or the nerves before enucleation of the mass, and, with the aim of minimizing any postoperative functional deficit, enucleation was started only after the monitored muscles showed no response to stimulation of the mass up to a level of $1.0 \mathrm{~mA}$ (Fig. 2B and C). In this manner, the surgeon was able to locate, identify, and map particular nerves and branches, and to decide the extent of enucleation. Nerve function and integrity after enucleation could also be checked (Fig. 2D). After the mass was excised, the surgical bed was irrigated with normal saline and a negative-pressure drain was inserted. Patients were discharged on the second day after removal of the drain.

\section{RESULTS}

The five cases analyzed are summarized in Table 1. Four male and one female patients were included. The chief complaint of all patients was a neck mass. All patients underwent surgery using the technique described above (Supplementary Figs. 1-5), and no patients had neurologic symptoms associated with the brachial plexus. The size of the tumor in cases $1-5$ was $2,1.6$, $1.8,6$, and $5.5 \mathrm{~cm}$, respectively. The tumor originated from the cord in two patients, the trunk in one patient, and the root in two patients. The two tumors originating from the root were larger than the others.

With neuromonitoring, one patient (case 1) did not show a response in the monitored muscles upon stimulation of the tumor. Cases 2 and 3 showed a response in the biceps brachii muscle, case 4 showed a response in the triceps brachii muscle, and case 5 showed responses in the diaphragm, biceps brachii, and triceps brachii muscles. Two patients experienced a temporary neurologic deficit: case 1 with mild motor dysfunction on grasping, which recovered in 1 month, and case 4 with sensory dysfunction of the forearm, which recovered in 2 months.

\section{DISCUSSION}

The brachial plexus is a nerve plexus formed by the anterior rami of the lower four cervical nerves and the first thoracic 
Table 1. Summary of five cases

\begin{tabular}{|c|c|c|c|c|c|c|c|}
\hline Case & Sex & $\begin{array}{l}\text { Age } \\
(y r)\end{array}$ & $\begin{array}{l}\text { Preoperative } \\
\text { finding }\end{array}$ & Origin & Muscles monitored & $\begin{array}{c}\text { Muscles stimulated around } \\
\text { the tumor }\end{array}$ & Postoperative outcome \\
\hline 1 & Male & 62 & $\begin{array}{c}\text { Neck mass, } \\
\text { neck pain }\end{array}$ & $\begin{array}{l}\text { Medial cord } \\
\text { (C8) }\end{array}$ & Biceps brachii, brachioradialis & - & $\begin{array}{l}\text { Mild motor dysfunction on } \\
\text { grasping for } 1 \text { month }\end{array}$ \\
\hline 2 & Male & 59 & Neck mass & $\begin{array}{l}\text { Upper trunk } \\
\text { (C5/6) }\end{array}$ & $\begin{array}{c}\text { Deltoid, biceps brachii, triceps } \\
\text { brachii, and brachioradialis }\end{array}$ & Biceps brachii & No neurologic deficit \\
\hline 3 & Male & 53 & Neck mass & $\begin{array}{l}\text { Lateral cord } \\
\qquad(\mathrm{C} 5 / 6 / 7)\end{array}$ & $\begin{array}{c}\text { Deltoid, biceps brachii, triceps } \\
\text { brachii, and brachioradialis }\end{array}$ & Biceps brachii & No neurologic deficit \\
\hline 4 & Female & 48 & $\begin{array}{l}\text { Neck mass } \\
\text { compressing } \\
\text { the lung }\end{array}$ & C7 root & $\begin{array}{c}\text { Deltoid, biceps brachii, triceps } \\
\text { brachii, and brachioradialis }\end{array}$ & Triceps brachii & $\begin{array}{l}\text { Temporary paresthesia of } \\
\text { forearm for } 2 \text { months }\end{array}$ \\
\hline 5 & Male & 56 & Neck mass & C6 root & $\begin{array}{c}\text { Deltoid, biceps brachii, triceps } \\
\text { brachii, and brachioradialis }\end{array}$ & $\begin{array}{l}\text { Diaphragm, biceps brachii, } \\
\text { and triceps brachii }\end{array}$ & No neurologic deficit \\
\hline
\end{tabular}

nerve. It is responsible for the motor innervation of the muscles of the upper extremity, and it can be divided into roots, trunks, divisions, cords, and branches (Fig. 1). The terminal branches of the brachial plexus are the musculocutaneous nerve, the axillary nerve, the radial nerve, the median nerve, and the ulnar nerve. The musculocutaneous nerve innervates the biceps brachii, brachialis, and coracobrachialis; the axillary nerve innervates the deltoid and teres minor; and the radial nerve innervates the triceps brachii, brachioradialis, anconeus, and the extensor muscles of the posterior arm and forearm.

Injury to the brachial plexus can result in severe motor and sensory dysfunction, with correspondingly diminished quality of life. Numerous studies conducted over the course of almost 50 years have described treatment outcomes and therapeutic approaches in patients with tumors of the brachial plexus, and postoperative functional deficits have been reported in $16 \%$ to $50 \%$ of cases $[9,10]$. Although there was a small number of patients in our study, none experienced permanent neurologic deficits after surgery. The rate of temporary postoperative neurologic dysfunction was $40 \%$ (2 of $5 ; 1$ each of motor and sensory dysfunction) (Table 1). Both of those patients reported minimal discomfort, and both recovered within 2 months.

Enucleation is an important procedure for preserving nerve function in the brachial plexus, and enucleation of schwannoma in the brachial plexus has been reported previously [11-13]. Surgical outcomes of enucleation of brachial schwannoma have been reported, and the risk of complete nerve injury was about $10 \%-20 \%$. Lee et al. [14] reported that $15 \%$ of patients had sensory changes and $10 \%$ had motor deficits immediately postoperatively; however, their deficits had improved at the last follow-up. Kehoe et al. [10], Ganju et al. [9], and Huang et al. [15] also reported postoperative problems in $17 \%, 22 \%$, and $22 \%$ of patients, respectively. However, intracapsular incision and enucleation can be difficult at times, and extracapsular excision can damage the normal fascicles during dissection of the capsule. We managed this challenge by using intraoperative neuromonitoring and by making a longitudinal incision on the tumor capsule where there were fewer neural fascicles. We used the
NIM device to assess neurologic function before and after removing the tumor in order to differentiate functional and nonfunctional tissues. When intraoperative EMG confirmed that an entrapped fascicle was nonfunctional, the fascicle could be resected with the tumor. In contrast, small pieces of tumor that were tightly adhered to a functional fascicle could be left unresected.

Intraoperative neuromonitoring is now widely used in head and neck surgical procedures, including mastoidectomy, parotidectomy, and thyroidectomy [16-18]. The technique provides benefits throughout the procedure by facilitating identification of the nerve, minimizing trauma to the nerve during dissection, and allowing final confirmation of neural integrity at the end of surgery. Our study demonstrated that intraoperative neuromonitoring during the enucleation of brachial plexus schwannoma is feasible and may be beneficial for the preservation of nerve function.

Intraoperative neuromonitoring enables the surgeon, especially the novice, to be confident during a procedure around a nerve. In procedures in which the identification of the nerve is paramount, such as thyroidectomy and parotidectomy, monitoring is essential, and although some controversy remains, intraoperative neuromonitoring may also be beneficial for bulky tumors and revision surgery, where dissection and direct visualization alone may prove insufficient. Moreover, intraoperative neuromonitoring has been associated with shorter operation times and higher levels of patient satisfaction [19,20]. A recent survey indicated that the most common reasons for using intraoperative neuromonitoring were to help identify the nerve, followed by medicolegal concerns and increased safety [21]. However, in enucleation of brachial plexus schwannoma, we think that the major advantage of intraoperative neuromonitoring is not nerve identification, because the mass can easily be found before identification of the brachial plexus. Instead, intraoperative neuromonitoring in this procedure is most beneficial for dissection around the nerves.

In thyroidectomy, the association of intraoperative neuromonitoring and the occurrence of postoperative vocal cord paralysis 
is significant because infrequent institutional use of intraoperative neuromonitoring has been correlated with higher rates of vocal cord paralysis [22]. In addition, better results of detailed voice parameters have been reported after surgery performed under intraoperative neuromonitoring [23]. The NIM system emits an audible signal and shows an EMG signal change even under subtle stimulation, such as traction or heating, that can cause nerve damage, which may be useful to prevent even minor trauma to the nerves. In most circumstances, as in our study, surgeons can halt the procedure to minimize the risk of injury to the relevant nerves when the NIM system indicates impending trauma and then resume the operation after confirming the safety of the nerve. We recommend draping the entire arm during surgery involving the brachial plexus to allow direct visualization of muscle stimulation (Fig. 2).

Despite its advantages in terms of early postoperative functional outcomes, most studies of intraoperative neuromonitoring lack long-term outcomes. A systematic review of parotidectomy revealed that intraoperative neuromonitoring decreased the risk of immediate postoperative facial nerve weakness, but did not appear to influence the final outcome of permanent facial nerve weakness [16]. Intraoperative neuromonitoring provides realtime feedback to reduce the occurrence of blunt trauma to the facial nerve and its branches, which may occur as a result of nerve manipulation, dissection, electrocautery, and instrumentation. By doing so, monitoring makes it more likely that nerves will recover from partial injury, but it should not increase the already high yield of identifying the trunk of the nerve and its major branches; therefore, monitoring should not be necessary to prevent complete transection of the nerve.

Although our study has the limitations of a small number of enrolled patients and a lack of sensory monitoring, it is the first to report the feasibility of intraoperative neuromonitoring during enucleation of brachial plexus schwannoma. Intraoperative neuromonitoring may help to reduce the risk of an early postoperative functional deficit. A further study with a larger cohort may clarify the advantages of intraoperative neuromonitoring in the surgical treatment of patients with brachial plexus schwannoma.

\section{CONFLICT OF INTEREST}

No potential conflict of interest relevant to this article was reported.

\section{ORCID}

Doh Young Lee https://orcid.org/0000-0003-1590-8559

Jeong-Yeon Chi https://orcid.org/0000-0002-7070-8560

Jungirl Seok https://orcid.org/0000-0001-6473-6015
Sungjun Han

Min-Hyung Lee

Woo-Jin Jeong

Young Ho Jung

https://orcid.org/0000-0002-9065-2082

https://orcid.org/0000-0002-4038-1667

https://orcid.org/0000-0001-8577-6964

https://orcid.org/0000-0002-3399-8167

\section{AUTHOR CONTRIBUTIONS}

Conceptualization: YHJ. Data curation: JYC, DYL. Formal analysis: JYC, DYL, YHJ. Methodology: JS, SH, MHL. Visualization: DYL, JYC, JS, YHJ. Writing original draft: DYL, JYC, YHJ. Writing review \& editing: WJJ, YHJ.

\section{SUPPLEMENTARY MATERIALS}

Supplementary materials can be found via https://doi.org/10. 21053/ceo.2019.01207.

\section{REFERENCES}

1. Biswas D, Marnane CN, Mal R, Baldwin D. Extracranial head and neck schwannomas: a 10-year review. Auris Nasus Larynx. 2007 Sep; 34(3):353-9.

2. Moukarbel RV, Sabri AN. Current management of head and neck schwannomas. Curr Opin Otolaryngol Head Neck Surg. 2005;13(2): 117-22.

3. Shrikrishna BH, Jyothi AC, Kulkarni NH, Mazhar MS. Extracranial head and neck schwannomas: our experience. Indian J Otolaryngol Head Neck Surg. 2016 Jun;68(2):241-7.

4. Zhang H, Cai C, Wang S, Liu H, Ye Y, Chen X. Extracranial head and neck schwannomas: a clinical analysis of 33 patients. Laryngoscope. 2007 Feb;117(2):278-81.

5. Liu HL, Yu SY, Li GK, Wei WI. Extracranial head and neck Schwannomas: a study of the nerve of origin. Eur Arch Otorhinolaryngol. 2011 Sep;268(9):1343-7.

6. Yasumatsu R, Nakashima T, Miyazaki R, Segawa Y, Komune S. Diagnosis and management of extracranial head and neck schwannomas: a review of 27 cases. Int J Otolaryngol. 2013;2013:973045.

7. Jia X, Yang J, Chen L, Yu C, KondoT. Primary Brachial plexus tumors: clinical experiences of 143 cases. Clin Neurol Neurosurg. 2016 Sep; 148:91-5.

8. Valentino J, Boggess MA, Ellis JL, Hester TO, Jones RO. Expected neurologic outcomes for surgical treatment of cervical neurilemomas. Laryngoscope. 1998 Jul;108(7):1009-13.

9. Ganju A, Roosen N, Kline DG, Tiel RL. Outcomes in a consecutive series of 111 surgically treated plexal tumors: a review of the experience at the Louisiana State University Health Sciences Center. J Neurosurg. 2001 Jul;95(1):51-60.

10. Kehoe NJ, Reid RP, Semple JC. Solitary benign peripheral-nerve tumours: review of 32 years' experience. J Bone Joint Surg Br. 1995 May;77(3):497-500.

11. Adani R, Baccarani A, Guidi E, Tarallo L. Schwannomas of the upper extremity: diagnosis and treatment. Chir Organi Mov. 2008 Sep; 92(2):85-8.

12. Park MJ, Seo KN, Kang HJ. Neurological deficit after surgical enucleation of schwannomas of the upper limb. J Bone Joint Surg Br. 2009 Nov;91(11):1482-6. 
13. Russell SM. Preserve the nerve: microsurgical resection of peripheral nerve sheath tumors. Neurosurgery. 2007 Sep;61(3 Suppl):113-7.

14. Lee HJ, Kim JH, Rhee SH, Gong HS, Baek GH. Is surgery for brachial plexus schwannomas safe and effective? Clin Orthop Relat Res. 2014 Jun;472(6):1893-8.

15. Huang JH, Zaghloul K, Zager EL. Surgical management of brachial plexus region tumors. Surg Neurol. 2004 Apr;61(4):372-8.

16. Sood AJ, Houlton JJ, Nguyen SA, Gillespie MB. Facial nerve monitoring during parotidectomy: a systematic review and meta-analysis. Otolaryngol Head Neck Surg. 2015 Apr;152(4):631-7.

17. Hu J, Fleck TR, Xu J, Hsu JV, Xu HX. Contemporary changes with the use of facial nerve monitoring in chronic ear surgery. Otolaryngol Head Neck Surg. 2014 Sep;151(3):473-7.

18. Bacuzzi A, Dralle H, Randolph GW, Chiang FY, Kim HY, Barczynski $\mathrm{M}$, et al. Safety of continuous intraoperative neuromonitoring (CIONM) in thyroid surgery.World J Surg. 2016 Mar;40(3):768-9.
19. Grosheva M, Klussmann JP, Grimminger C, Wittekindt C, Beutner D, Pantel $\mathrm{M}$, et al. Electromyographic facial nerve monitoring during parotidectomy for benign lesions does not improve the outcome of postoperative facial nerve function: a prospective two-center trial. Laryngoscope. 2009 Dec;119(12):2299-305.

20. Eisele DW,Wang SJ, Orloff LA. Electrophysiologic facial nerve monitoring during parotidectomy. Head Neck. 2010 Mar;32(3):399-405.

21. Lowry TR, GalTJ, Brennan JA. Patterns of use of facial nerve monitoring during parotid gland surgery. Otolaryngol Head Neck Surg. 2005 Sep;133(3):313-8.

22. Chung TK, Rosenthal EL, Porterfield JR, Carroll WR, Richman J, Hawn MT. Examining national outcomes after thyroidectomy with nerve monitoring. J Am Coll Surg. 2014 Oct;219(4):765-70.

23. Baek SK, Lee K, Oh D, Kang SH, Kwon SY,Woo JS, et al. Efficiency of intraoperative neuromonitoring on voice outcomes after thyroid surgery. Auris Nasus Larynx. 2017 Oct;44(5):583-59. 